\title{
EFFECT OF PHASE FEEDING ON BROILER PERFORMANCE
}

\author{
Tamador A. ALGAM ${ }^{1 \times \mathbb{}}$, Rashid H. OSMAN 2 , Wafaa Babiker ZOMRAWI ${ }^{3}$ and Mojahid A. ABDALHAG 1 \\ ${ }^{1}$ Faculty of Agricultural Technology \& Fish Science, Al Neelain University, Khartoum, Sudan \\ 2 faculty of Animal Production, West Kordofan University, El Nuhud, Sudan \\ ${ }^{3}$ Faculty of Agriculture and Natural Resources, University of Bakht Elruda, Sudan \\ Email: tamaraalgam@yahoo.com; (1) ORCiD: 0000-0002-9491-6399 \\ Supporting Information
}

\begin{abstract}
This study was conducted to assess the effects of phase feeding on growth performance of broiler chicks. The experimental work consisted of a 7-week trial feeding, in which three different feeding programme. Three experimental diets formulated to contain different levels of metabolizable energy (ME) and crude protein (CP); namely a broiler starter diet containing approximately $3072 \mathrm{Kcal} \mathrm{ME} / \mathrm{kg}$ and $23.9 \%$ crude protein, a grower diet containing $3118 \mathrm{Kcal} \mathrm{ME} / \mathrm{Kg}$ and $21.8 \%$ crude protein, and a finisher diet containing $3200 \mathrm{Kcal} \mathrm{ME} / \mathrm{kg}$ and $18 \%$ crude protein. The results diets not reveal any significant differences in productive parameters, but indicated marked trends in differences among the experimental treatment. These differences showed that the highest feed consumption and live weight gain were attained by the group of birds fed the starter diet throughout the experimental period. The starter diet followed by the finisher diet for four weeks resulted in the lowest total feed consumption, reasonably high body weight gain, lowest feed conversion ratio and highest dressing percentage. It can, however, be considered under the conditions of the present experiment that the three experimental feeding programmes supported similar productive performance of broiler, indicating a slight economic advantage of feeding the starter diet followed by the finisher diet.
\end{abstract}

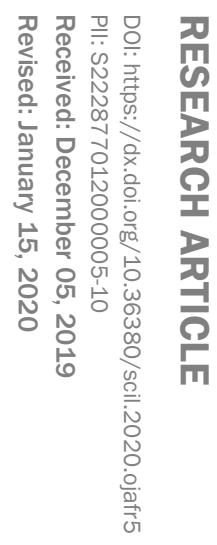

Keywords: Broiler chicken, Growth performance, Phase feeding

\section{INTRODUCTION}

Feed constitutes approximately 60-70\% of total broiler production costs (Saveewonlop, 2019). The broiler industry has been developed into the most efficient animal production sector. This development has been brought about through development and advancement of research in the fields of poultry science and related subjects. The most significant of these developments were in the fields of genetics and nutrition, which lead to the breeding of commercial broiler chicks capable of rapid growth and efficient utilization of feed (Anonymous 2013; Mehmood et al., 2014). Since feed cost constitutes the major cost item of producing broiler meat, considerable research effort was concentrated in improving nutrition and efficiency of feed utilization of the broiler chicks. The broiler chicks are known to be exacting in their nutrient requirements for rapid growth and development, and that they need to be supplied with adequate diets capable of satisfying these requirements in a utilizable form (Skinner-Noble et al., 2001).

The nutrient requirements of boiler chicks have been almost precisely established and the capacity of various feed ingredients to supply these nutrients has been identified, and consequently the formulations of adequate diets became possible. The broiler chick has some extremely high nutrient requirements, particularly during the early stages of its growth. The capacity of the digestive system of the chick is very limited during this period, and it became important to feed them diets highly concentrated in metabolizable energy and protein of high quality, beside high levels of vitamins and essential minerals during the early stages of the growing period. Such diets have been commercially established and used world- wide. These high density broiler diets were recommended to be fed as a sole diet for the whole 6-7 weeks growing period (Skinner-Noble et al., 2001).

Further research development indicated that the nutrient requirements of the broiler chicks vary with its advancement of growth according to the increase in body weight and nature of growth. The growth curve established that young broiler chicks during the first 3-4 weeks of life are at their most active phase of growth, and the nature of growth during this period is mostly in the form of tissue protein and very little fat (Skinner-Noble et al., 2001). Accordingly, it has been indicated to vary the composition of broiler diets during the growing period according to the actual nutrient requirements for the changing nature of growth. In this context, different feeding programmes with varying dietary nutrient composition have been developed for the growing broilers as a means for economy of feed and efficient nutrient utilization, and ultimate reduction of the cost of feeding. In this respect, different diets of variable nutrients composition have been advocated for phase feeding of broilers, based on increasing the energy content of the diet and reducing its crude protein content with the advancement of age (Roush et al. 2004). It is intended in this study to assess the effect of phase feeding using different feeding programmes, on the production performance and carcass yield of broilers. 


\section{MATERIALS AND METHODS}

\section{Experimental diets}

Three types of starter, grower and finisher broiler diets were formulated from the local feed ingredients and imported super concentrate which used as complement dietary protein, amino acids, vitamins and minerals. The composition of the super concentrate was described in table 1. The diets were formulated according to the recommended nutrient composition of the diets commonly used in phase feeding of broiler chicks. In this respect, the starter diet was relatively high in metabolizable energy (ME) and crude protein content, which were reduced in the grower diet, the protein content was further reduced in the finisher diet with increasing the ME content. The formulation of the experimental diets is shown in table 2. The calculated and proximate analyses were shown in tables 3 and 4 , respectively. Each diet was analyzed for its content of dry matter, crude protein, ether extract and crude fiber according to the procedure of AOAC (1980) for proximate analysis. The metabolizable energy (ME) content of the diets were calculated according to the equation of Lodhi (1976) based on the determined proximate analyses values of the diets. The equation is as fallow:

M.E (Kcal kg-1= (1.549+0.102(CP) +0.275(EE)+0.148(N.F.E)-0.034(C.F) X239.

The calculated analyses of the diets were made according to the tables of NRC (1994) for ingredients composition.

Table 1 - The chemical composition of the super concentrate used in the formulation of the experimental diets (LNB concentrate 5\%)

\begin{tabular}{lc} 
Analysis & Min. \\
\hline Crude protein \% & 40.00 \\
Metabolizable Energy kcal/kg & 2100 \\
Crude fiber \% & 2.00 \\
Calcium \% & 10.00 \\
Phosphorus total \% & 4.00 \\
Lysine \% & 12.00 \\
Methionine \% & 3.00 \\
Methionine + Cysteine \% & 3.20 \\
\hline
\end{tabular}

\section{Table 2 - The formulation of the experimental diets (percent as fed).}

\begin{tabular}{|c|c|c|c|}
\hline Ingredient & Experimental diets $\quad$ Starter & Grower & Finisher \\
\hline Sorghum & 60.0 & 67 & 76.41 \\
\hline Groundnut meal & 18.0 & 14 & 10 \\
\hline Sesame meal & 14.85 & 11.8 & 6 \\
\hline Super-concentrate & 5.0 & 5 & 5 \\
\hline Crushed oyster shell & 1.5 & 1.5 & 1.5 \\
\hline Common salt & 0.3 & 0.3 & 0.3 \\
\hline Methionine & 0.1 & 0.15 & 0.21 \\
\hline Lysine & 0.25 & 0.25 & 0.25 \\
\hline Vegetable oil & - & - & 0.33 \\
\hline Total & 100.0 & 100.0 & 100.0 \\
\hline
\end{tabular}

\section{Table 3 - The calculated analyses of the experimental diets (percent as fed)}

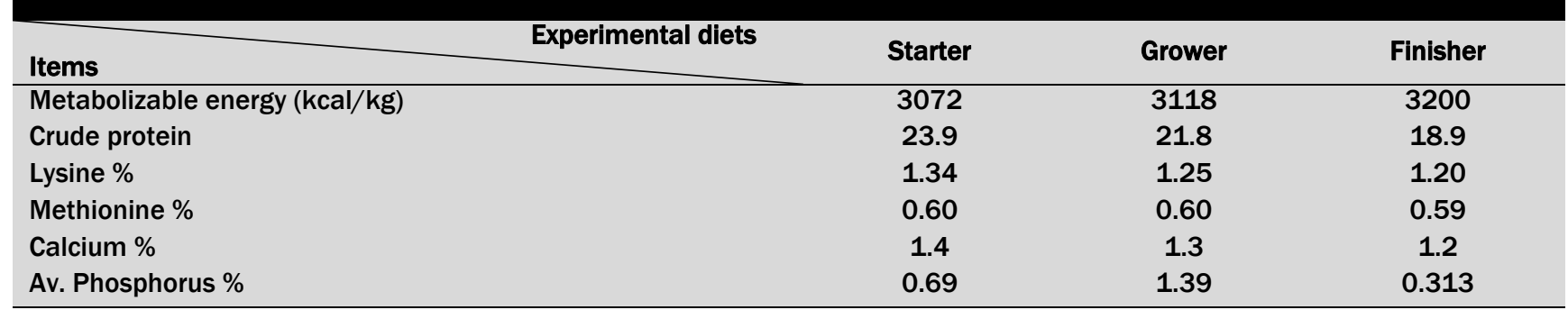

\section{Table 4 - Proximate analysis of the experimental diets (percent)}

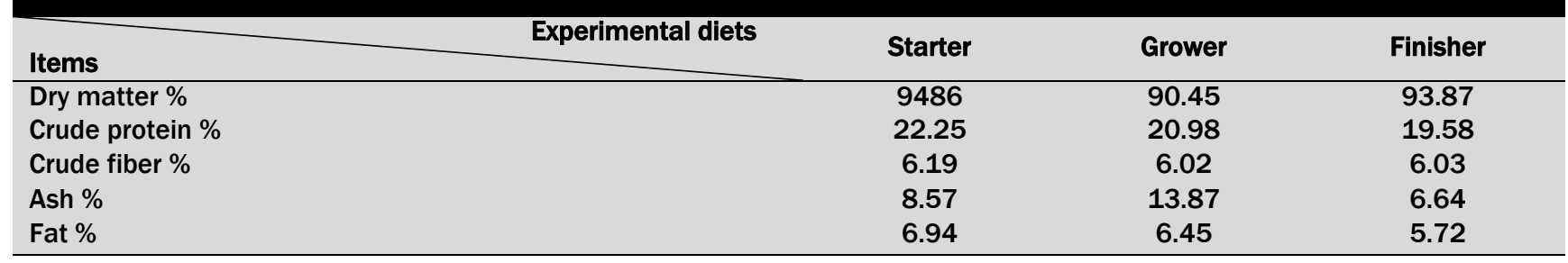




\section{Birds and management}

A total of 120 unsexed day-old broiler chicks of commercial strain (Hubbard) were purchased from a local hatchery (Coral C0.) The birds were reared on deep litter in an open side house; the experimental house was apportioned in to 9 pens of equal area $(1 \times 1 \mathrm{~m})$. The pens were arranged in three rows, each row containing three pens, each pen was equipped with a tube feeder and a fountain waterer. Upon arrival, the chicks were immediately given sugar in drinking water to reduce the transportation stress. At two weeks of the age the chicks were vaccinated against Newcastle Disease.

\section{Experimental procedure}

Birds were randomly assigned to the experimental pens at the rate of 10 chicks per pen. The three experimental treatments were randomly assigned to each row of pens (block), thus giving a Randomized Complete Block Design arrangement. Treatment 1 consisted starter diet from day-old. Birds were fed starter diet for the first two weeks followed by the grower diet for 2 weeks and then the finisher diet to the end of the experiment ( 7 week). Treatment 3 consisted starter diet from day old to 3 weeks of age followed by the finisher diet to the end of the experiment. Feed consumption and live weight weekly determined for each pen, and mortality was recorded as it occurred. At the end of the experiment the birds were fasted overnight except for water. Three birds from each replicate (pen) were randomly selected, wing tagged and individually weighed. They were then slaughtered by jugular severing and left for an appropriate time to bleed. The birds were eviscerated and hot dressed carcass weight was recorded. The data for weekly feed consumption, live weight gain, feed conversion ratio and dressing percentage were collected. The data was analyzed statistically for treatment differences by analysis of variance for the randomized complete block design according to Steel et al. (1980).

\section{RESULT AND DISCUSSION}

Performance results did not show significant differences in total feed consumption, live weight gain or feed conversion efficiency among the experimental birds. These results are in line with several reports on the effects of phase feeding of broiler chicks by Warren and Emmert (2000); Pope and Emmert (2001); Skinner-Noble et al. (2001); Pope et al. (2002); Roush et al. (2004); N. Saveewonlop (2019). They indicated that phase feeding can support similar feed intake growth, carcass yield and feed efficiency to that of feeding a single starter diet based on NRC recommendations. Despite the insignificant differences in performance among the different feeding programmes, the results revealed certain trends in insignificant differences in performance among the experimental feeding programmes. The highest feed intake and live weight gain were attained by feeding the single starter diet throughout the experimental period, while feeding the starter diet accompanied by the grower and finisher diets resulted in the lowest body weight gain; and feeding the starter diet followed by the finisher diet to the end of the experimental period resulted in the lowest feed intake and lowest feed conversion ratio. These trends in performance generally follow the pattern of nutrients intake, resulting from the differences in feed consumption of the experimental diets. In this respect, the intake of all essential nutrients was highest under programme I, where the chicks were fed the nutrient dense starter diet during the whole experimental period. This was followed by the birds reared on programme 2, and was least on phase feeding programme 3 . No differences in feed intake, body weight gain, or feed conversion efficiency were observed among the experimental birds during the three weeks starting period. This can be attributed to the fact that all the birds during this period received the same starter diet and almost consumed the same amounts of feed and nutrients. The amount of feed consumed during this period was only a small fraction of the total feed consumed by the birds over the 7 weeks' growth period. Consequently, the highest amount of feed and nutrients were consumed during the grower and finisher periods, thus having a greater impact on body weight gain and feed utilization during the later phases of the growth period. These effects were clearly marked in the works of Warren and Emmert (2000), Skinner-Noble et al. (2001), Roush et al. (2004), Tremarin \& Sakamoto (2017), and Saveewonlop (2019). These workers indicated that body weight and feed conversion were not sensitive to the grower diet feeding in a three- diets phase feeding programme.

\section{Table 5 - Summary table of performance of the experimental birds during 0-7 weeks of age (g/bird/7week)}

\begin{tabular}{|c|c|c|c|c|}
\hline Treatments & 1 & 2 & 3 & SE \\
\hline Number of bird/treatment & 30.0 & 30.0 & 30.0 & - \\
\hline Initial body weight (g/bird) & 40.90 & 43.60 & 42.30 & - \\
\hline Total feed consumption & 3306.60 & 3080.6 & 3021.6 & 90.68 NS \\
\hline Final live body weight ( $\mathrm{g} /$ bird) & 1390.0 & 1317.0 & 1349.0 & 95.87 NS \\
\hline Live body weight gain (g/bird/ 7) & 1349.1 & 1253.4 & 1306.7 & 39.96 NS \\
\hline Feed conversion ratio ( $\mathrm{g}$ feed/g) & 2.45 & 2.45 & 2.31 & $0.055 \mathrm{NS}$ \\
\hline Dressing percentage & 68.30 & 69.80 & 72.7 & 2.92 NS \\
\hline Cost of feed consumed (SD) & 291.80 & 297 & 296.1 & $-N S$ \\
\hline
\end{tabular}




\begin{tabular}{lccc}
\hline Items & Treatments & $\mathbf{2}$ & 3 \\
\hline ME Kcal & 10132 & 9575 & 9587 \\
Crude protein & 788 & 669 & 566 \\
Lysine & 44 & 38 & 35 \\
Methionine & 19 & 18 & 17 \\
Calcium & 48 & 42 & 37 \\
Av. Phosphorus & 11 & 10 & 9 \\
Values are means of 30 birds/treatment; NS= not statistically significant, SE= Standard error of means; 1= starter diet; 2= starter diet + \\
grower diet + finisher diet; 3= starter diet + finisher diet.
\end{tabular}

On the other hand, increasing the starter diet feeding period had the strongest effect on increasing body weight and decreasing feed conversion ratio; while decreasing the feeding period of the finisher diet increased the body weight and decreased the feed conversion ratio. It has also been indicated that broiler performance under phase feeding programmes is influenced by the length of the growing period and the proportion of time that the starter, grower and finisher diets are fed, as well as the stage of growth at which these diets are introduced. The absence of significant differences among the results of the present study indicates that the three tested feeding programmes were capable of supporting similar productive performance of broilers. This is irrespective of the marked differences in nutrients intake, particularly crude protein and lysine. This, however, did not reflect any differences in the cost of feed consumed under the different feeding programmes, due to the unexceptionally high prices of grain sorghum in the particular season, which was used at high percentages in the grower and finisher diets this result similar with those reported by Ajighjigh (2018). Under normal price conditions, the cost of feeding will be lowest in the programme which consisted of feeding the starter diet followed by the finisher diet. The same programme seemed to be more appropriate for supporting broiler production in the light of the attained lowest feed consumption, reasonably high live weight gain and lowest feed conversion ratio among the experimental treatments.

\section{CONCLUSIONS}

The absence of significant differences among the results of the present study indicates that the three tested feeding programmes were capable of supporting similar productive performance of broilers. This is irrespective of the marked differences in nutrients intake, particularly crude protein and lysine. This did not reflect any differences in the cost of feed consumed under the different feeding programmes. It can be considered that the conditions of the present experiment though limited, reflects the advantage of phase feeding of broiler chicks, particularly the programme of feeding the starter diet followed by finisher diet.

\section{DECLARATIONS}

Corresponding author

E-mail: tamaraalgam@yahoo.com

Authors' contributions

All authors were contributed equally.

Competing interests

The authors declare that they have no competing interests.

\section{REFERENCES}

Ajighjigh DT, Mahmud M and Waziri D (2018) Growth Performance and Economics of Production of broiler chickens fed Agro Industrial by-products. IOSR Journal of Agriculture and Veterinary Science, 11: 87-92. PDF

Anonymous (2013) Economic Survey of Pakistan (2012-13). (Ministry of Finance, Finance Division, Economics Advisor's Wing., Government of Pakistan, Islamabad Pakistan), pp. 30. Link

AOAC (1980) Official Methods of Analysis (13 th ed.). Association of Official Analytical Chemists, Method, p. 521. Washington, DC, 31.111.

Lodhi GN, Singh D, Ichhponani JS (1976) Variation in nutrient content of feedingstuffs rich in protein and reassessment of the chemical method for metabolizable energy estimation for poultry. The Journal of Agricultural Science, 86(2): 293303. Google Scholar 
Mehmood S, Sahota A, Akram M, Javed K, Hussain J, Shaheen M, Abbas Y, Jatoi A and lqbal A (2014) Growth performance and economic appraisal of phase feeding at different stocking densities in sexed broilers. Journal of Animal and Plant Sciences, 24: 714-21. Google Scholar

Saveewonlop N, Rattanatabtimtong S, Ruangpanit Y, Songserm O, Attamangkune S (2019) Effects of different phasefeeding programs with different feed forms on broiler growth performance, carcass traits and intestinal morphology. Poultry Science, 18(4): 181-6. Google Scholar

NRC (1994) Nutrient requirement of poultry. National Academy press, Washington, DC. 9th rev. ed.

Pope T and Emmert JL (2001) Phase-feeding supports maximum growth performance of broiler chicks from forty-three to seventy-one days of age. Poultry Science, 80: 345-52. Google Scholar

Pope T, Loupe L, Townsend J and Emmert JL (2002) Growth performance of broilers using a phase-feeding approach with diets switched every other day from forty-two to sixty-three days of age. Poultry Science, 81: 466-71. Google Scholar

Roush BW, Deborah B \& Branton SL (2004). Optimization of phase feeding of starter, grower, and finisher diets for male broilers by mixture experimental design: forty-eight-day production period. Poultry Science, 83: 1264-75. Google Scholar

Skinner-Noble D, Berry J \& Teeter R (2001) Use of a single diet feeding program for female broilers. Animal Science Research Report, Oklahoma University. Google Scholar

Stell RG, Torrie JH, Dickey D (1980) Principles and procedures of statistics: a biometrical approach. New York: MacGrawHill. 1980. Google Scholar

Tremarin J and Sakamoto M (2017) Feeding Programs for Broiler Breeders in the Start Phase. Brazilian Journal of Poultry Science, 19: 125-30. Google Scholar

Warren W and Emmert J (2000) Efficacy of phase-feeding in supporting growth performance of broiler chicks during the starter and finisher phases. Poultry Science, 79: 764-70. Google Scholar 